\title{
A dimensionless framework for predicting submarine fan morphology
}

\author{
Abdul Wahab ( $\nabla$ awahab@tulane.edu ) \\ Tulane University \\ David Hoyal \\ Upstream Research Company, ExxonMobil \\ Mrugesh Shringarpure \\ Upstream Research Company, ExxonMobil \\ Kyle Straub \\ Tulane University
}

\section{Article}

Keywords: submarine fan morphology, climate, environment

Posted Date: May 28th, 2021

DOI: https://doi.org/10.21203/rs.3.rs-506377/v1

License: (c) (1) This work is licensed under a Creative Commons Attribution 4.0 International License. Read Full License 


\section{A dimensionless framework for predicting submarine fan}

\section{2 morphology}

3 Abdul Wahab ${ }^{1 *}$, David C. Hoyal ${ }^{2}$, Mrugesh Shringarpure ${ }^{2}$, \& Kyle M. Straub ${ }^{1}$

$4{ }^{1}$ Department of Earth and Environmental Sciences, Tulane University, New Orleans, LA 70118,

5 USA.

$6 \quad{ }^{2}$ Upstream Research Company, ExxonMobil, Houston, TX, 77389

7 Correspondence to Abdul Wahab (awahab@tulane.edu)

8 A remarkable diversity exists in the morphology and dynamics of submarine fans, which

9 influence the transport of microplastics, burial of organic carbon, subsea geo-hazards, and

10 their potential to house geofluids and high-resolution paleo-environmental records. Like river

11 deltas, submarine fan morphology is a product of evolving fluid and sediment transport fields,

12 but unlike their terrestrial counterparts we lack a unifying framework to predict their

13 morphology. Here, we simplify critical environmental forcings, like regional slopes and

14 sediment properties, through a dimensionless framework defined by the densimetric Froude

15 number (ratio of inertial to gravitational forces) and Rouse number (ratio of settling velocity

16 of sediments to shear velocity) of turbidity currents. We explore this framework by leveraging

17 a depth-averaged numerical model and measure fan rugosity as a proxy for their

18 morphological complexity. We show a systematic increase in rugosity by either increasing the

19 densimetric Froude number or decreasing the Rouse number of the simulated flows. These 
21 discriminate submarine fans that have the potential to impact global climate through sequestration of organic carbon.

23 Submarine fans form on continental slopes and abyssal plains in deepwater settings and are the

24 ultimate sinks in sediment routing systems. They are crafted by turbidity currents, which arguably

25 move more sediment on Earth than any other transport process and their deposits preserve the

26 thickest accumulations of sediment on Earth ${ }^{1}$. Like deltas, the morphologies of submarine fans are

27 quite variable $e^{2-4}$ and largely result from the dynamics of the channels which move over their

28 surfaces. Unlike deltas, where we have predictive theory for their morphology $y^{5,6}$, we lack a physics-

29 informed theory that successfully predicts the array of observed submarine fan morphologies. This

30 is critical as the surface dynamics that produce these morphologies influence the fidelity of climate

31 change records housed in their strata ${ }^{7}$, the frequency and severity of geohazards that threaten

32 subsea infrastructures such as the network of seafloor cables that hosts the majority of global data

33 traffic ${ }^{8,9}$, and voluminous geofluid reservoirs ${ }^{10}$. We also highlight the importance of flows that

34 traverse submarine fans for global climate as they influence the dispersal of microplastics that

35 impacts ocean carbon sequestration ${ }^{11-14}$ and the burial and preservation of transported particulate

36 organic carbon ${ }^{15,16}$.

37 Turbidity currents are dilute sediment-gravity flows in which the driving gravitational

38 force is supplied by turbulently suspended sediments ${ }^{17}$. These currents can travel for $10^{2}$ hours and

39 up to $10^{3}$ kilometers in deepwater settings $(\sim>4000 \mathrm{~m})^{18,19}$, which makes direct monitoring of 
modern currents challenging. Further complicating the matter, our ability to infer paleo-hydraulic

41 and sediment-transport regimes from the strata of ancient fans is limited. While physical

42 experiments provided insight into interactions of turbidity currents with an antecedent bed

43 topography ${ }^{20-22}$ over short timescales, we lack experimental methods to produce self-channelized

44 submarine fans constructed by fully turbulent flows that transport most of their sediment in 45 suspension.

We overcome the direct observational and experimental limitations that prevent us from

47 linking properties of turbidity current to the morphology of submarine fans by leveraging a

48 physics-based and parallel numerical model. This model simulates the interactions of a depth-

49 averaged turbidity current (Fig. 1a) with a uniform and non-erodible antecedent surface (Fig. 1b).

50 We investigate the hypothesis that submarine fan shape is largely controlled by regional

51 bathymetric slopes and the properties of sediments (size and cohesion) delivered to submarine

52 fans. We achieve this by solving continuity equation ${ }^{23}$ for fluid mass, sediment mass, momentum,

53 and turbulent kinetic energy for turbidity currents: in addition to erosion and deposition of

54 cohesive sediments ${ }^{24}$ and flocculation of mud particles ${ }^{25,26}$. A steady current enters through an inlet

55 channel into a square domain that is scaled by the advection length of the mean grain size in

56 suspension. In this manner, our models simulate currents that rapidly lose confinement downslope

57 of a canyon or channel-to-fan transition. To isolate the influence of flow hydraulics and sediment 
59 climatic forcings (i.e. sea-level, water flux, and sediment supply) within model runs. Simulations

60 are stopped after a defined volume of sediment is released into the model domain.

\section{The dimensionless regime}

62 Classification systems exist for submarine fans based on characteristics of the terrestrial feeder

63 system $^{27}$, preserved grain sizes ${ }^{28,29}$, facies associations ${ }^{30-32}$, and preserved morphology ${ }^{33,34}$. These

64 classification schemes leverage observations that fans on high slopes (e.g. Squamish fan) are

65 generally small $(<10$ 's of $\mathrm{km})$ and sandy ${ }^{3,35}$, intermediate slope fans (e.g. Gulf of Cadiz) contain

66 both sand and $\mathrm{mud}^{4}$, and fans that form on low slopes (e.g. Zaire fan) are large (>1000 km) and

67 rich in mud content ${ }^{2,36}$. While the studies that underpin these classification systems report

68 correlations for parameters that influence fan shape, they generally carry tremendous scatter,

69 which limits their predictive power. Many of these classification systems assume links to the

70 hydraulics and sediment-transport capacity of turbidity currents, but we lack theory that explicitly

71 links fan shape to flow processes.

We propose a dimensionless regime (Fig. 2) where submarine fan dynamics and resulting

73 morphology are defined by two dimensionless variables, the densimetric Froude number $\left(\mathrm{Fr}_{\mathrm{D}}\right)$ and

74 Rouse number (Ro) that weigh competing forces in turbidity currents. $\operatorname{Th} \mathrm{Fr}_{\mathrm{D}}$ quantifies the ratio

75 of inertial to gravitational forces within a flow, while the Ro describes the ratio of settling velocity

76 of sediments to shear velocity in the flow. To explore this regime, we solve for an equilibrium slope,

77 which we set as our initial bathymetric gradient, from a choice of $\mathrm{Fr}_{\mathrm{D}}$ as function of bed friction 
78 and clear water entrainment ${ }^{37}$. We compute for mean grain sizes in suspension at the inlet from a

79 choice of Ro as a function of their settling velocity. While $\mathrm{Fr}_{\mathrm{D}}$ and Ro are free to change over the

80 evolving fan surface, we classify fans based on their inlet $\mathrm{Fr}_{\mathrm{D}}$ and $\mathrm{Ro}$ values. To capture a wide

81 range of morphodynamic behaviors, we explore ranges in $\mathrm{Fr}_{\mathrm{D}}$ and $\mathrm{Ro}$ for a depth-averaged

82 turbidity current (Table 1). To avoid either highly erosional or depositional flows, we performed

83 sensitivity analyses that guided the range of conditions explored.

\section{End member morphodynamics}

85 The submarine fans in our regime diagram have morphologies and surface dynamics that are

86 defined by $\mathrm{Fr}_{D}$ and Ro and display striking similarity to their field counterparts. Here we focus on

87 a comparison of fans constructed by subcritical $\left(\mathrm{Fr}_{\mathrm{D}}<1\right)$ flows with low Ro values to supercritical

$88 \quad\left(\mathrm{Fr}_{\mathrm{D}}>1\right)$ flows with high Ro values.

Our model captures both large and small-scale geomorphic features of subcritical and low

90 Ro fans that are preserved on low slopes (e.g., Zaire ${ }^{2,36,38}$ ) (Fig. 3a). We observe multiple sinuous

91 channels bound by prominent levees. These fans are crafted by channel networks that fluctuate

92 between one-to-many active channels. The channels generate a distributive pattern by avulsing at

93 a variety of distances from the inlet channel. On the levees, flow tends to locally change criticality

94 and induce formation of cyclical steps. We observe a hierarchy of bifurcations with genetically

95 related mouth bar deposits that help partition flux of sediment and water moving through the

96 growing distributive network. This partitioning is variable and leads to the formation of 
97 asymmetric branching channels. In these fans, sand is mainly transported in channels, while silts

98 and muds are deposited on levees, lobes, and distal parts of the outer fan.

100 At the channel-mouth bar transition the flow undergoes a hydraulic jump, where the increased

101 flow height and loss of turbulence lead to deposition of sediments in the form of cyclical steps ${ }^{39}$.

102 These cyclical bedforms (Fig. 3b) migrate upstream in the channel until the flow confinement

103 decreases and an avulsion is triggered. This type of fan is predominantly sandy because flow shear

104 stresses inhibit deposition of silt and mud. The absence of flux partitioning at the channel-mouth

105 bar transition and avulsions triggered in a single channel system that visit many locations through

106 time induces an overall radial fan shape.

107 Submarine fan shape and texture

108 The shape of submarine fans and the size of the particles they house provide insight into the

109 hydraulics and sediment transport capacity of the flows that constructed them. Here we focus on

110 the planform complexity of submarine fans and use regional bathymetric slopes (or slope estimates

111 for paleo-fans) and deposit grain sizes to constrain the $\mathrm{Fr}_{\mathrm{D}}$ and Ro responsible for constructing a

112 given fan. First, we quantify the rugosity of submarine fans as a proxy for the complexity of their

113 morphologies. Contrary to deltas, where the shoreline represents an important contour for delta

114 front deposition ${ }^{6}$, there is no established contour that reflects the influence of forcing conditions

115 on submarine fan shape. We overcome this by utilizing a deposit thickness contour that delineates 
116 the depositional midpoint in submarine fans. Specifically, we use a mass-balance transformation ${ }^{40}$,

117 which measures downstream distance in terms of sediment mass lost to deposition in a basin. We

118 define a dimensionless mass extraction parameter, $\chi$, as:

$$
\chi(r)=\frac{1}{V_{s, b}} \int_{0}^{L} B(r) H_{s}(r) d r
$$

119 Where $V_{s, b}$ is the total volume of sediment stored in the basin, $L$ is the total downstream length of

120 a basin, $B$ is the basin width at a radial distance measured from the end of the entrance channel $r$,

121 and $H_{s}$ is the average thickness of preserved strata along a strike transect defined by $r$. The value of

$122 \chi$ ranges between 0 and 1 , for instance, a value of 0.5 implies that half of the sediment stored in a

123 basin is upstream of that location. We compute for a semicircle with an origin at the end of the

124 inlet channel and a radius equivalent to $\chi=0.5$. We contour the fan based on the mean deposit

125 thickness on this semi-circle and evaluate its rugosity as,

$$
R(\chi=0.5)=\frac{1}{N} \sum_{i=1}^{n} \frac{\left|r_{c}-r_{\text {mid }}\right|}{r_{\text {mid }}}
$$

127 where $N$ is the number of deposit thickness maps, $n$ is number of $\mathrm{x}-\mathrm{y}$ locations on the semicircle,

$128 r_{c}$ is the radial distance between the origin of the semicircle and an $\mathrm{x}-\mathrm{y}$ location on the mean

129 thickness contour, and $r_{\text {mid }}$ is the radius of the $\chi=0.5$ semicircle (Fig. $4 \mathrm{a}$ ). We exclude models that

130 exhibit near complete sediment bypass.

The simulations show a systematic increase in planform roughness, quantified through

132 rugosity, as one explores from the low $\mathrm{Fr}_{\mathrm{D}}$ and high Ro corner of the regime diagram towards the 
133 high $\operatorname{Fr}_{D}$ and low Ro domain (Fig. 4b). We interpret the joint influence of $F_{D}$ and Ro on fan

134 rugosity as thus. Given fans of constant $\mathrm{Fr}_{\mathrm{D}}$, decreasing Ro results in longer transport distances for

135 particles in suspension, allowing active and relatively stable channels to quickly prograde. In

136 addition, decreasing Ro leads to more poorly sorted sediments, due to our inlet suspension criteria

137 (see methods). Like prior research on deltaic channels ${ }^{6}$, we propose that an increase in sorting

138 promotes more frequent and asymmetric channel bifurcations, leading to multiple active channels.

139 While this increase in active channels facilitates the delivery of sediment to more fan locations, the

140 stable and asymmetric nature of these channels results in jagged contours with high rugosity

141 values.

Traversing our regime along paths of constant Ro but increasing $\mathrm{Fr}_{\mathrm{D}}$ corresponds to higher

143 shear velocities (Fig. 5, extended) for flows of equivalent thickness at the inlet, which inhibits

144 deposition of silts and finer sands and promotes the maintenance of fewer active channels. These

145 channels terminate in a single large mouth bar deposit covered with backstepping cyclical

146 bedforms. This promotes channel mobility through infrequent avulsions caused by the loss of

147 confinement due to the backstepping bedforms. As a result, fan rugosity increases due to the

148 elongation of the relatively active few channels, contrary to the processes responsible for increasing

149 rugosity through decreasing Ro. However, as $\mathrm{Fr}_{\mathrm{D}}$ increases past criticality sediment bypass

150 conditions are reached and further increases in $\mathrm{Fr}_{\mathrm{D}}$ produce unfavorable conditions for channel

151 initiation and maintenance. 
While rugosity alone is not a unique indicator of $\mathrm{Fr}_{\mathrm{D}}$ and $\mathrm{Ro}$, fan rugosity coupled with

153 knowledge of one of these parameters allows for the estimation of the other. For example, the

154 rugosity of modern submarine fans can be estimated with high resolution bathymetric and shallow

155 seismic surveys, whereas for ancient fan deposits it can be estimated with industry-grade 3-D

156 seismic surveys. $\mathrm{Fr}_{\mathrm{D}}$ can then be estimated with the regional (paleo)slopes and existing empirical

157 functions for drag coefficients and clear water entrainment ${ }^{37}$, as implemented in our model. Fan

158 rugosity and $\mathrm{Fr}_{\mathrm{D}}$ can then be used to invert for the Ro of the inlet flow to a fan. Furthermore,

159 sediment sizes suspended in the inlet flow can be estimated from knowledge of the feeder channel

160 depth. This would involve estimating the shear velocity of the inlet flow from channel depth and

$161 \mathrm{Fr}_{\mathrm{D}}$, followed by use of the Ro to solve for sediment sizes in transport through a settling velocity.

163 for the inversion of $\mathrm{Fr}_{\mathrm{D}}$. Here, the challenge is to estimate a paleo-flow Ro of the feeder channel.

164 This can be done with access to statistics of deposit grain sizes, for example from core

165 measurements. This would entail using an assumption that the largest preserved particles met a

166 Shield's criterion, which could be used to invert for a shear velocity. The Ro can then be calculated

167 with a characteristic settling velocity of the median particle size in transport. To accomplish this,

168 we found and utilized an empirical relationship (see methods) between fan rugosity and a ratio

169 formed by the sizes of the median particles in transport to the median size in the deposit (Fig. 6).

170 Results from our dimensionless regime diagram have implications beyond the morphology

171 of submarine fans. We highlight our results that suggest flows traversing high slope submarine fans 
172 are efficient at transporting fine sediments that can include microplastics. As a result, microplastics

173 could preferentially bypass these fans and get diffused into the deep oceans. Deep water currents

174 can further redistribute microplastics along with terrigenous sourced nutrients, which severely

175 impacts the ability of phytoplankton to fix $\mathrm{CO}_{2}$ via photosynthesis ${ }^{13}$. Microplastics ingested by

176 these phytoplankton can also negatively impact marine food-webs and the rate of particulate

177 carbon production and preservation ${ }^{12-14}$.

On the contrary, modern fans on low slopes often have complex morphologies, suggesting

179 they were constructed by low $\mathrm{Fr}_{\mathrm{D}}$ and Ro flows. Our regime diagram indicates that these fans

180 efficiently trap mud supplied by turbidity currents. A high fraction of sediment in the mud size

181 range $(<62.5 \mathrm{um})$ consists of clays whose mineral surface properties ${ }^{41}$ favors adsorption of

182 particulate organic carbon, which can be preserved if rapidly buried to only several cms of depth.

183 This suggest that subcritical fans on low slope settings can impact global climate by sequestering

184 large volumes of carbon.

185

186 


\section{Methods}

191 In the interest of capturing a range of morphodynamic behaviors within submarine fans that are

192 defined by different slopes and mean grain sizes, we propose a dimensionless regime space. This is

193 achieved by defining the horizontal axis of the regime space as $\mathrm{Fr}_{\mathrm{D}}$, which quantifies the ratio of

194 inertial to gravitational forces within a turbidity current. It is calculated as $F r_{D}=u / \sqrt{R g c h}$, using

195 depth-average values for important forcing variables within the flow, such as velocity $(u)$,

196 concentration $(c)$, and height of the current $(h)$. We set $c=5 \%, h=5 m, R=1.65$, and $g=$

$1979.8 \mathrm{~m} / \mathrm{s}^{2}$ at the inlet, and therefore, by varying $\mathrm{Fr}_{\mathrm{D}}$ we only vary the velocity magnitude at the inlet.

198 We compute for an equilibrium slope ${ }^{44} S=\left(\left(e_{w}+c d\right) * F r_{D}^{2}+0.5 * e_{w}\right)$, as a function of

199 friction at the bed and clear water entrainment from a choice of $\mathrm{Fr}_{\mathrm{D}}$, where $e_{w}$ is the clear water

200 entrainment coefficient, calculated from the $\mathrm{Fr}_{\mathrm{D}}{ }^{37}$, and $c d$ is the coefficient of friction with a fixed

201 value of 0.004 . On the vertical axis, we define the $R o=w_{s} /\left(k * u_{*}\right)$, which quantifies the ratio of

202 settling velocity of sediments $\left(w_{s}\right)$ to shear velocity $\left(u_{*}\right)$ in the flow, where $k$ is von Karmen's

203 constant. We compute the mean settling velocity of sediments $<w_{s}>$ from a choice of Ro using

204 the Dietrich ${ }^{42}$ method, which then allows us to indirectly compute for the grain sizes in suspension

205 (Fig. 5a extended). We compute a lognormal distribution sampled by 10 quartz sediment sizes with

206 a 5 um clay particles ( $10 \%$ of the total sediment concertation) added to the final sediment mixture.

207 We compute sorting (Fig. 5b extended) for this log normal distribution by leveraging the shields

208 curve of suspension, such that $D_{99}$ or finer sediment sizes will honor the Bagnold Criterion ${ }^{17}$. We 
209 conducted sensitivity analyses on the dimensional variables that defines $\mathrm{Fr}_{\mathrm{D}}$ and $\mathrm{Ro}$. In these

210 models, we found similar absolute values for fan rugosity in experiments with different

211 dimensional scales, but equivalent dimensionless scales. Next, we performed sensitivity analyses

212 to examine how the percent of the total sediment concentration comprised of clay particles

213 influences the absolute magnitude of resulting morphology metrics. We find that relative to

214 models documented here, which utilized a mud fraction of $10 \%$, changing mud content between

215 over a range of $5-60 \%$ did change the placement of channels and lobe, but only changed the

216 absolute values of fan rugosity by at most $17 \%$. As such, a third axis defined by mud content could

217 be generated for our regime diagram to account for erosion and deposition dynamics imparted by

218 the cohesive fraction of the sediment concentration. However, this third axis is likely less

219 significant for fan rugosity than the axes defined by $\mathrm{Fr}_{\mathrm{D}}$ and $\mathrm{Ro}$.

We scale the simulation domain size by leveraging a modified version of the advection

221 length, $l a=\left\langle u>* h_{c} / w_{s}\right.$, which describes the minimum horizontal distance over which the

222 mean grain size within a flow can be transported before making contact with the bed ${ }^{43}$. In this

223 formulation, $\left\langle u>\right.$ is the depth-average velocity of the flow at the inlet, $h_{c}$ describes the height of

224 the center of mass within a turbidity current. This height is calculated as, $h_{c}=h *$

$225(0.5 * z c+0.25(1-z c))$, where $h$ is the height of the current at the inlet, and $z c$ is the

226 normalized distanced from the bed to the maximum volumetric concentration in the flow, and is

227 set to 0.9 when $F r_{D}<0.5$ and $z c=0.09 * F r_{D}{ }^{-2.8}$ when $F r_{D}>0.5^{44}$. 
229 irregular network (TIN) grid of average $50 \mathrm{~m}$ mesh. For post-processing we interpolate the data

230 onto a Cartesian grid. The entrance channel and upstream boundary walls are closed (and reflect

231 flows), whereas the side and downstream boundaries are open and allow flows to exit the domain.

232 We implement a model stopping condition by fixing the total volume of sediment released into

233 the domain at $2.5 \times 10^{07}$ cubic meters. As a result, subcritical cases require longer computation run-

234 time due to relatively low velocity magnitudes, whereas supercritical simulations take relatively

235 shorter times, given the rapid delivery of the set amount of total sediment volume.

The simulator uses a four equation model ${ }^{23}$ that solves for bedload fluxes ${ }^{45}$, erosion rates ${ }^{46}$,

237 deposition rates ${ }^{47}$, flocculation of clay particles ${ }^{25,26}$, and the influence of cohesion on the underlying

238 deposit $^{24}$. Models are run with a dynamic time step that is a function of grid spacing, flow velocity,

239 and wave speed.

240 Our method to invert for fan forming flow $\mathrm{Fr}_{\mathrm{D}}$ from Ro and fan rugosity takes advantage

241 of deposit grain size statistics. We highlight a gradient in our regime diagram of a ratio between

242 median particle sizes in transport to the median particle sizes preserved in the fan, GS $S_{\text {Ratio. }}$ This

243 gradient is in the same direction as the observed gradient in fan rugosity as a function of $\mathrm{Fr}_{\mathrm{D}}$ and

244 Ro. An empirical relationship was then fit to allow for estimation of $\mathrm{GS}_{\text {Ratio }}$ from fan rugosity (Fig.

2456 extended). 


\section{References}

2481 Talling, P. J. et al. Key Future Directions For Research On Turbidity Currents And Their

249 Depositskey Future Directions For Research On Turbidity Currents And Their Deposits.

250 Journal of Sedimentary Research 85, 153-169 (2015).

2512 Babonneau, N., Savoye, B., Cremer, M. \& Klein, B. Morphology and architecture of the

252 present canyon and channel system of the Zaire deep-sea fan. Marine and Petroleum

253 Geology 19, 445-467 (2002).

2543 Sweet, M. L. et al. Sediment routing from shelf to basin floor in the Quaternary Golo System

255 of Eastern Corsica, France, western Mediterranean Sea. Bulletin 132, 1217-1234 (2020).

2564 Habgood, E. L. et al. Deep-water sediment wave fields, bottom current sand channels and

257 gravity flow channel-lobe systems: Gulf of Cadiz, NE Atlantic. Sedimentology 50, 483-510

$258 \quad$ (2003).

2595 Nienhuis, J. et al. Global-scale human impact on delta morphology has led to net land area

260 gain. Nature 577, 514-518 (2020).

2616 Caldwell, R. L. \& Edmonds, D. A. The effects of sediment properties on deltaic processes

262 and morphologies: A numerical modeling study. Journal of Geophysical Research: Earth

$263 \quad$ Surface 119, 961-982 (2014).

2647 Hessler, A. M. \& Fildani, A. Deep-sea fans: tapping into Earth's changing landscapes.

265 Journal of Sedimentary Research 89, 1171-1179 (2019). 
2668 Heezen, B. C. \& Ewing, W. M. Turbidity currents and submarine slumps, and the 1929

267 Grand Banks [Newfoundland] earthquake. American journal of Science 250, 849-873

$268 \quad(1952)$.

2699 Carter, L., Gavey, R., TALLING, P. J. \& Liu, J. T. Insights into submarine geohazards from

270 breaks in subsea telecommunication cables. Oceanography 27, 58-67 (2014).

27110 Weimer, P. \& Pettingill, H. S. Global overview of deep-water exploration and production.

$272 \quad$ (2007).

27311 Kane, I. A. et al. Seafloor microplastic hotspots controlled by deep-sea circulation. Science

$274 \quad 368,1140-1145(2020)$.

27512 Wright, S. L., Thompson, R. C. \& Galloway, T. S. The physical impacts of microplastics on 276 marine organisms: a review. Environmental pollution 178, 483-492 (2013).

27713 Shen, M. et al. Can microplastics pose a threat to ocean carbon sequestration? Marine $278 \quad$ pollution bulletin 150, $110712(2020)$.

27914 Cole, M. et al. Microplastics alter the properties and sinking rates of zooplankton faecal 280 pellets. Environmental science \& technology 50, 3239-3246 (2016).

28115 Galy, V. et al. Efficient organic carbon burial in the Bengal fan sustained by the Himalayan 282 erosional system. Nature 450, 407-410 (2007).

28316 Hage, S. et al. Efficient preservation of young terrestrial organic carbon in sandy turbidity284 current deposits. Geology 48, 882-887 (2020). 
28517 Bagnold, R. A. Auto-suspension of transported sediment; turbidity currents. Proceedings 286 of the Royal Society of London. Series A. Mathematical and Physical Sciences 265, 315-319 287 (1962).

28818 Azpiroz-Zabala, M. et al. Newly recognized turbidity current structure can explain 289 prolonged flushing of submarine canyons. Science advances 3, e1700200 (2017).

29019 Pirmez, C. \& Imran, J. Reconstruction of turbidity currents in Amazon Channel. Marine 291 and petroleum geology 20, 823-849 (2003).

29220 Imran, J., Parker, G. \& Harff, P. Experiments on incipient channelization of submarine 293 fans. Journal of Hydraulic Research 40, 21-32 (2002).

29421 Parsons, J. D. et al. A preliminary experimental study of turbidite fan deposits. Journal of 295 Sedimentary Research 72, 619-628 (2002).

29622 Straub, K. M. \& Mohrig, D. Quantifying the morphology and growth of levees in aggrading 297 submarine channels. Journal of Geophysical Research: Earth Surface 113 (2008).

29823 Parker, G., Fukushima, Y. \& Pantin, H. M. Self-accelerating turbidity currents. Journal of $299 \quad$ Fluid Mechanics 171, 145-181 (1986).

30024 Winterwerp, J. C. \& Van Kesteren, W. G. Introduction to the physics of cohesive sediment 301 dynamics in the marine environment. (Elsevier, 2004).

30225 Kuprenas, R., Tran, D. \& Strom, K. A shear-limited flocculation model for dynamically 303 predicting average floc size. Journal of Geophysical Research: Oceans 123, 6736-6752 304 (2018). 
30526 Winterwerp, J. C. A simple model for turbulence induced flocculation of cohesive 306 sediment. Journal of hydraulic research 36, 309-326 (1998).

30727 Clark, J., Kenyon, N. \& Pickering, K. Quantitative analysis of the geometry of submarine 308 channels: implications for the classification of submarine fans. Geology 20, 633-636 (1992).

30928 Richards, M., Bowman, M. \& Reading, H. Submarine-fan systems I: characterization and $310 \quad$ stratigraphic prediction. Marine and Petroleum Geology 15, 689-717 (1998).

31129 Stow, D. A. \& Mayall, M. Deep-water sedimentary systems: new models for the 21st 312 century. Marine and Petroleum Geology 17, 125-135 (2000).

31330 Bouma, A. H. Sedimentology of some flysch deposits. Agraphic approach to facies $314 \quad$ interpretation $168(1962)$.

31531 Lowe, D. R. Sediment gravity flows; II, Depositional models with special reference to the 316 deposits of high-density turbidity currents. Journal of sedimentary research 52, 279-297 $317 \quad$ (1982).

31832 Mutti, E. \& Ricci Lucchi, F. Turbidites of the northern Apennines: introduction to facies 319 analysis. International geology review 20, 125-166 (1978).

32033 Vail, P. The stratigraphic signatures of tectonics, eustacy and sedimentology-an overview. $321 \quad$ Cycles and events in stratigraphy, 617-659 (1991).

32234 Shanmugam, G. Glossary: A supplement to "Submarine fans: A critical retrospective 323 (1950-2015)" in the Journal of Palaeogeography (2016, 5 [2]). Journal of Palaeogeography 324 5, 258-277 (2016). 
32535 Cornard, P. H. \& Pickering, K. T. Supercritical-flow deposits and their distribution in a 326 submarine channel system, middle Eocene, Ainsa Basin, Spanish Pyrenees. Journal of 327 Sedimentary Research 89, 576-597 (2019).

32836 Picot, M., Droz, L., Marsset, T., Dennielou, B. \& Bez, M. Controls on turbidite 329 sedimentation: insights from a quantitative approach of submarine channel and lobe 330 architecture (Late Quaternary Congo Fan). Marine and Petroleum Geology 72, 423-446 $331 \quad$ (2016).

33237 Parker, G., Garcia, M., Fukushima, Y. \& Yu, W. Experiments on turbidity currents over an 333 erodible bed. Journal of Hydraulic Research 25, 123-147 (1987).

33438 Deptuck, M. E. \& Sylvester, Z. in Submarine geomorphology 273-299 (Springer, 2018).

33539 Hamilton, P. B., Strom, K. B. \& Hoyal, D. C. Hydraulic and sediment transport properties 336 of autogenic avulsion cycles on submarine fans with supercritical distributaries. Journal of 337 Geophysical Research: Earth Surface 120, 1369-1389 (2015).

33840 Strong, N., Sheets, B., Hickson, T. \& Paola, C. in Fluvial sedimentology VII Vol. 35 243339253 (International Association of Sedimentologists Special Publication 35, 2005).

34041 Mayer, L. M. Surface area control of organic carbon accumulation in continental shelf 341 sediments. Geochimica et Cosmochimica Acta 58, 1271-1284 (1994).

34242 Dietrich, W. E. Settling velocity of natural particles. Water resources research 18, 1615$343 \quad 1626(1982)$. 
34443 Ganti, V., Lamb, M. P. \& McElroy, B. Quantitative bounds on morphodynamics and

345 implications for reading the sedimentary record. Nature communications 5, 1-7 (2014).

34644 Sequeiros, O. E. Estimating turbidity current conditions from channel morphology: A

347 Froude number approach. Journal of Geophysical Research: Oceans 117 (2012).

34845 Meyer-Peter, E. \& Müller, R. in IAHSR 2nd meeting, Stockholm, appendix 2. (IAHR).

34946 Garcia, M. \& Parker, G. Entrainment of bed sediment into suspension. Journal of Hydraulic

$350 \quad$ Engineering 117, 414-435 (1991).

35147 Garcia, M. H. Depositional turbidity currents laden with poorly sorted sediment. Journal 352 of hydraulic engineering 120, 1240-1263 (1994).

35348 Vendettuoli, D. et al. Daily bathymetric surveys document how stratigraphy is built and its 354 extreme incompleteness in submarine channels. Earth and Planetary Science Letters 515, $355 \quad 231-247(2019)$.

356 


\section{Acknowledgements}

363 This study is funded by Upstream Research Company, ExxonMobil. We greatly acknowledge 364 members of Process Stratigraphy at URC, for providing training and access to high performance 365 computing tools to the author for generating the dataset utilized in this campaign.

\section{Author contributions}

367 The authors contributed to this manuscript as follows, D.C.H, KM.S, M.S and A.W conceived of

368 this study and developed the theoretical framework; A.W carried out the numerical work with

369 assistance and guidance from M.S; A.W processed and interpreted the data; D.C.H, M.S, and

370 K.M.S reviewed the interpretations; A.W and K.M.S wrote the manuscript with feedback from

371 D.C.H and M.S.

372 Competing Interests

373 The authors declare no competing interests.

374 Additional Information

375 Extended data for this paper is available at [To be decided]

376 Correspondence and requests for materials should be addressed to A.W.

\section{Data availability}

378 Data will be made available as per Nature Geoscience guidelines. 
a)
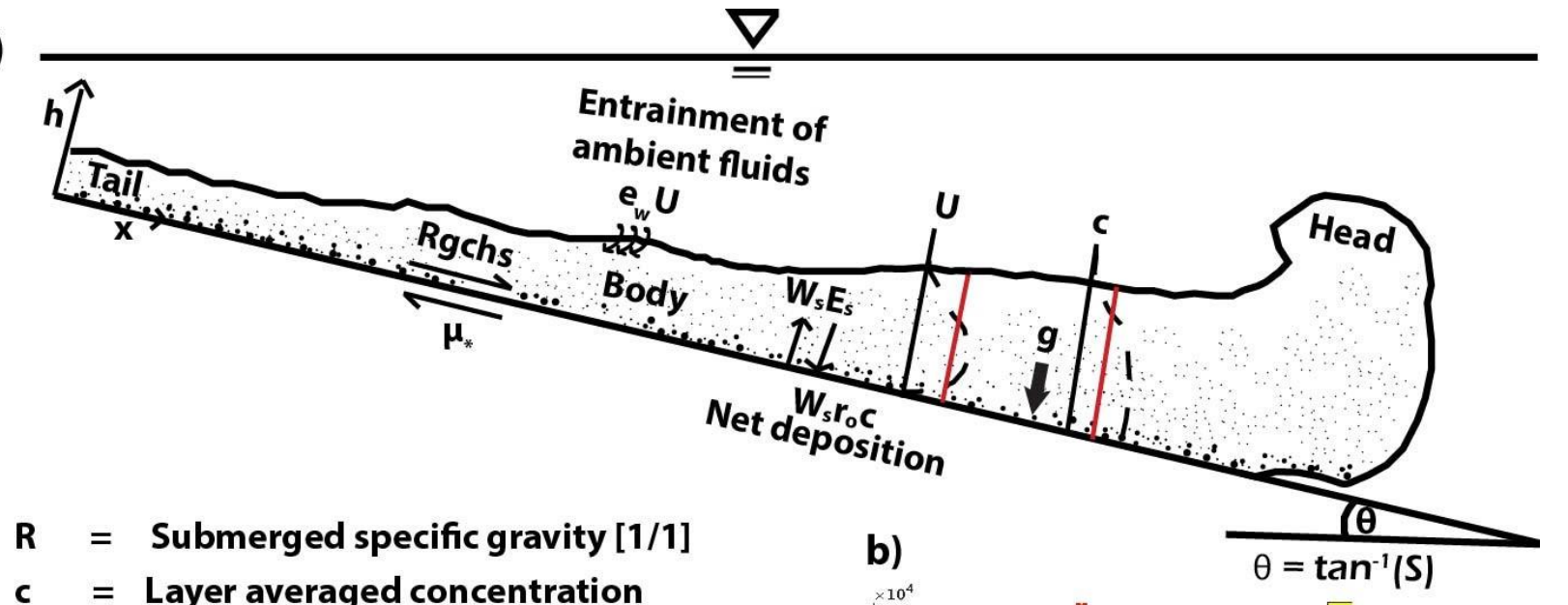

$\mathbf{u}_{*}=$ Shear velocity $[\mathrm{m} / \mathrm{s}]$

$e_{w}=$ Entrainment coefficient [1/1]

$U=$ Velocity $[\mathrm{m} / \mathrm{s}]$

$\mathbf{W}_{\mathrm{s}}=$ Settling velocity $[\mathrm{m} / \mathrm{s}]$

$E_{s}=$ Errosion coefficient [1/1]

$r_{0}=$ Sediment concentrated at base flow

$h=$ Height of the current [m]

S = Slope [degree]

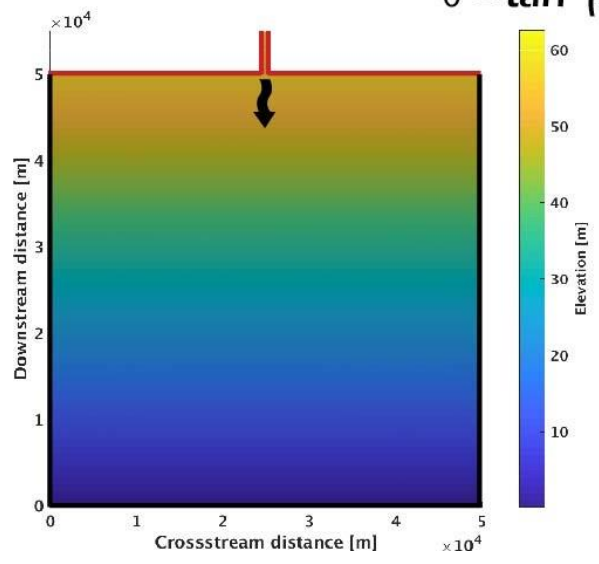

381 Fig.1 | Numerical setup. a, Schematic cross-section of a turbidity current with important depth382 averaged terms highlighted in red. b, Example of a model domain with a flat non-erodible slope. 383 Red lines trace upstream boundaries of domain that are closed and reflect flow, whereas black lines 384 trace boundaries that are open and allow the flow to exit the domain. The black arrow represents 385 the debouchment of flow from the inlet channel and dominant flow direction. 
Case ID $\mathrm{Fr}_{\mathrm{D}}{ }^{1} \quad \mathrm{Ro}^{2}$ Slope $\mathrm{U}^{3} \quad \mathrm{u}_{*}{ }^{4} \quad \mathrm{D}^{2} 0^{5} \quad \mathrm{Dmax}^{6}$ Sorting $\mathrm{Ws}^{7}{ }^{8}$ Duration $[1 / 1][1 / 1]$ degree $[\mathrm{m} / \mathrm{s}][\mathrm{m} / \mathrm{s}][\mathrm{um}] \quad[\mathrm{um}][1 / 1][\mathrm{m} / \mathrm{s}]$ [hour]

\begin{tabular}{ccccccccccc}
\hline 1 & 0.46 & 0.032 & 0.001 & 0.9 & 0.06 & 24 & 463 & 1.8 & 0.002 & 30210 \\
3 & 0.63 & 0.032 & 0.002 & 1.3 & 0.08 & 25 & 645 & 2.0 & 0.003 & 22088 \\
6 & 1.00 & 0.032 & 0.008 & 2.0 & 0.13 & 23 & 1178 & 2.4 & 0.004 & 13809 \\
7 & 1.17 & 0.032 & 0.013 & 2.4 & 0.15 & 22 & 1497 & 2.6 & 0.005 & 11807 \\
9 & 1.60 & 0.032 & 0.036 & 3.2 & 0.20 & 17 & 2632 & 3.1 & 0.007 & 8633 \\
31 & 0.46 & 0.101 & 0.001 & 0.9 & 0.06 & 83 & 463 & 1.1 & 0.006 & 30210 \\
33 & 0.63 & 0.101 & 0.002 & 1.3 & 0.08 & 94 & 645 & 1.2 & 0.008 & 22088 \\
36 & 1.00 & 0.101 & 0.008 & 2.0 & 0.13 & 109 & 1178 & 1.5 & 0.013 & 13809 \\
37 & 1.17 & 0.101 & 0.013 & 2.4 & 0.15 & 113 & 1497 & 1.6 & 0.015 & 11807 \\
39 & 1.60 & 0.101 & 0.036 & 3.2 & 0.20 & 114 & 2632 & 1.9 & 0.021 & 8633 \\
51 & 0.46 & 0.148 & 0.001 & 0.9 & 0.06 & 115 & 463 & 0.9 & 0.009 & 30210 \\
53 & 0.63 & 0.148 & 0.002 & 1.3 & 0.08 & 135 & 645 & 1.0 & 0.012 & 22088 \\
56 & 1.00 & 0.148 & 0.008 & 2.0 & 0.13 & 165 & 1178 & 1.2 & 0.019 & 13809 \\
57 & 1.17 & 0.148 & 0.013 & 2.4 & 0.15 & 175 & 1497 & 1.3 & 0.022 & 11807 \\
59 & 1.60 & 0.148 & 0.036 & 3.2 & 0.20 & 188 & 2632 & 1.6 & 0.030 & 8633 \\
71 & 0.46 & 0.194 & 0.001 & 0.9 & 0.06 & 145 & 463 & 0.7 & 0.011 & 30210 \\
73 & 0.63 & 0.194 & 0.002 & 1.3 & 0.08 & 172 & 645 & 0.8 & 0.015 & 22088 \\
76 & 1.00 & 0.194 & 0.008 & 2.0 & 0.13 & 219 & 1178 & 1.0 & 0.025 & 13809 \\
77 & 1.17 & 0.194 & 0.013 & 2.4 & 0.15 & 235 & 1497 & 1.1 & 0.029 & 11807 \\
79 & 1.60 & 0.194 & 0.036 & 3.2 & 0.20 & 265 & 2632 & 1.4 & 0.039 & 8633 \\
91 & 0.46 & 0.240 & 0.001 & 0.9 & 0.06 & 173 & 463 & 0.6 & 0.014 & 30210 \\
93 & 0.63 & 0.240 & 0.002 & 1.3 & 0.08 & 207 & 645 & 0.7 & 0.019 & 22088 \\
96 & 1.00 & 0.240 & 0.008 & 2.0 & 0.13 & 270 & 1178 & 0.9 & 0.031 & 13809 \\
97 & 1.17 & 0.240 & 0.013 & 2.4 & 0.15 & 294 & 1497 & 1.0 & 0.036 & 11807 \\
99 & 1.60 & 0.240 & 0.036 & 3.2 & 0.20 & 341 & 2632 & 1.3 & 0.049 & 8633 \\
\hline & & & & & & & \\
73 &
\end{tabular}

${ }^{1}$ Densimetric Froude Number : ${ }^{2}$ Rouse Number : ${ }^{3}$ Mean velocity at the inlet: ${ }^{4}$ Mean shear velocity at the inlet : ${ }^{5}$ Mean sand diameter

'Maximum sand diameter : Mean settling vlocity of suspended material at the inlet : * Total simulation time on a super computer

387 Table 1. | Select model variables used in this study. 


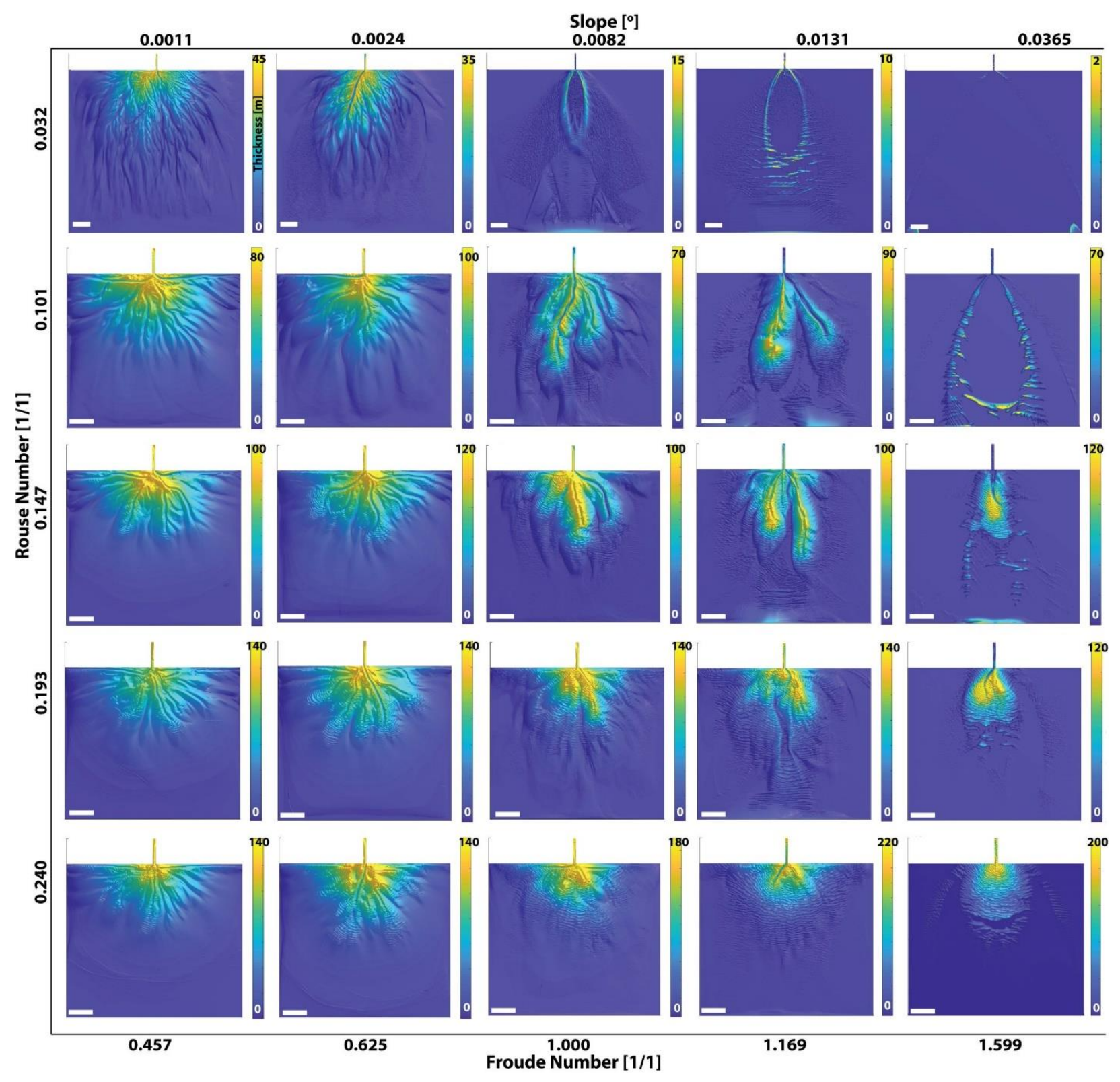

389 Fig.2 | Dimensionless regime diagram. A subset of simulated fans displays different planform 390 morphologies that result from defined combinations of $\mathrm{Fr}_{\mathrm{D}}$ and Ro. Note that range of fan 391 thicknesses displayed in color and the horizontal scale vary between models. Models in the first 392 row have domain size of $55 \times 50 \mathrm{~km}$ whereas the remaining models have a domain size of $35 \times 30$ $393 \mathrm{~km}$. White bar denotes $5 \mathrm{~km}$ of length. Additional variables are listed in Table 1. 


\section{a) Subcritcal fan}
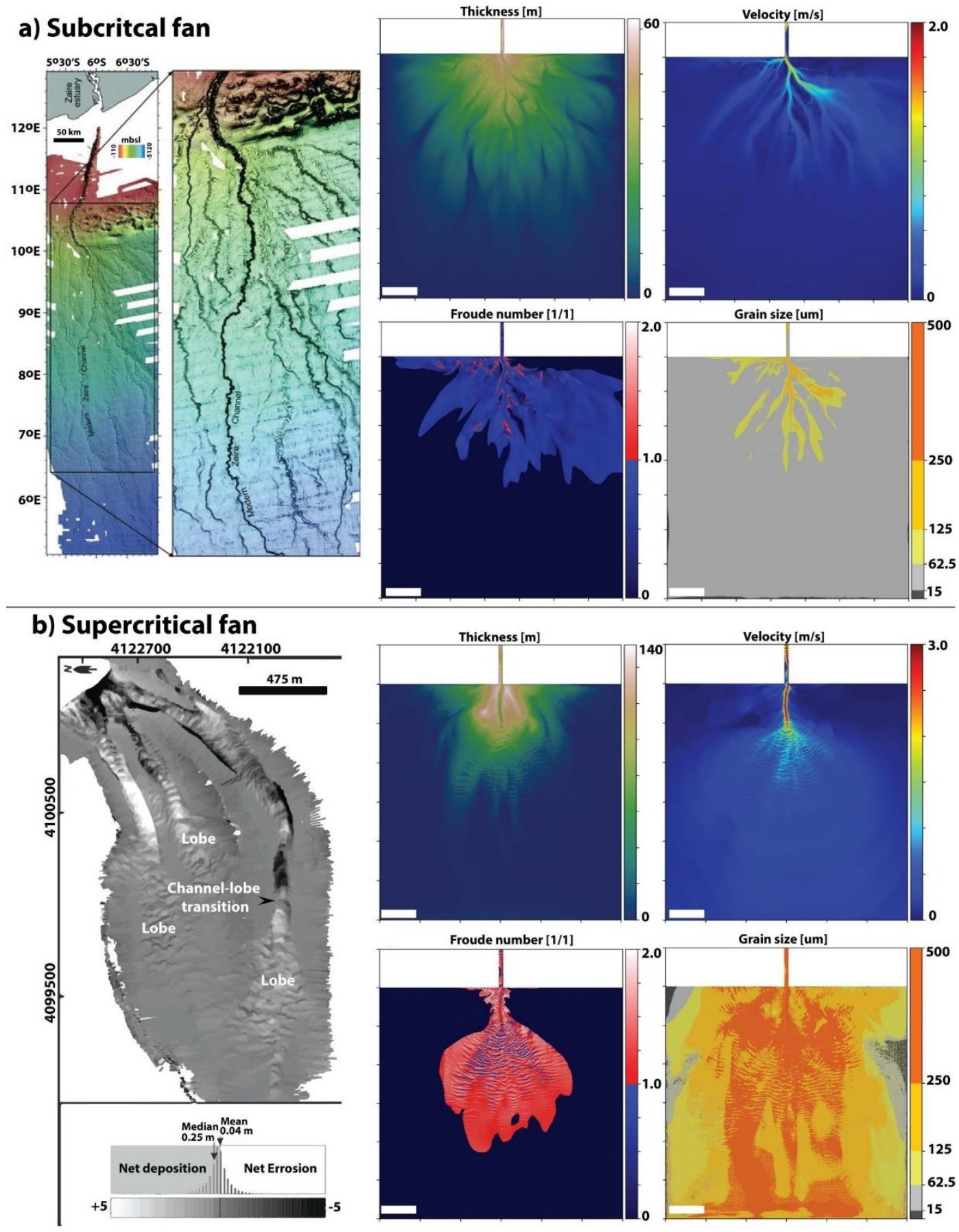

395 Fig.3 | Comparison of endmember model behavior to field analogs. a, Deposit thickness (m), 396 velocity (m/s), $F_{D}$ state, and grain sizes (um) in the subcritical simulation ( $\left.40 \times 35 \mathrm{~km}\right)$ indicate; a 397 distributive transport pattern, multiple active and sinuous channels, a hierarchy of bifurcations, 398 and overall mud rich deposit that resembles aspects of the Zaire fan $^{38}$ (left panel). b, Supercritical 399 fan simulation ( $35 \times 30 \mathrm{~km}$ ) shows characteristic cyclical bedforms formed due to a hydraulic jump, 400 a single active and low-sinuosity channel, and sand rich deposit that resembles a high slope modern $401 \mathrm{fan}^{48}$ (Left panel). White color bar is $5 \mathrm{~km}$. See movies for these runs in supplemental materials. 
a)
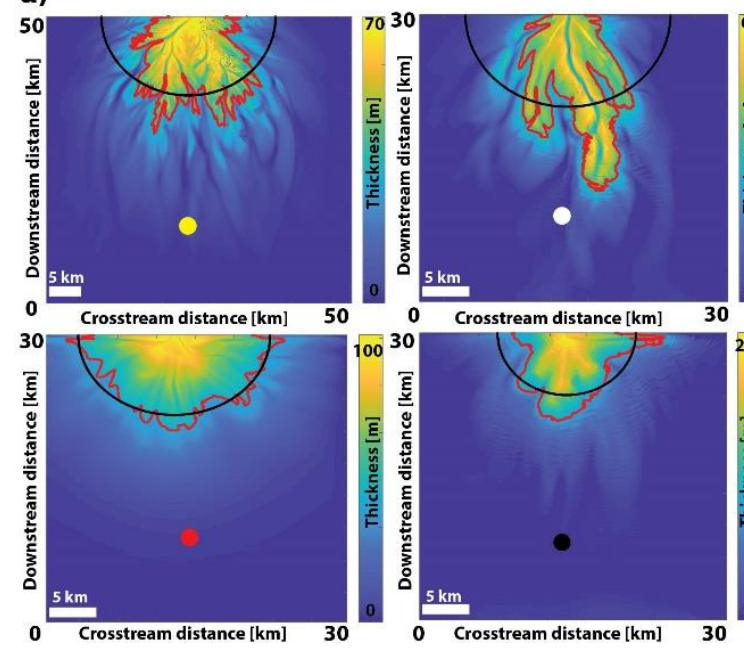
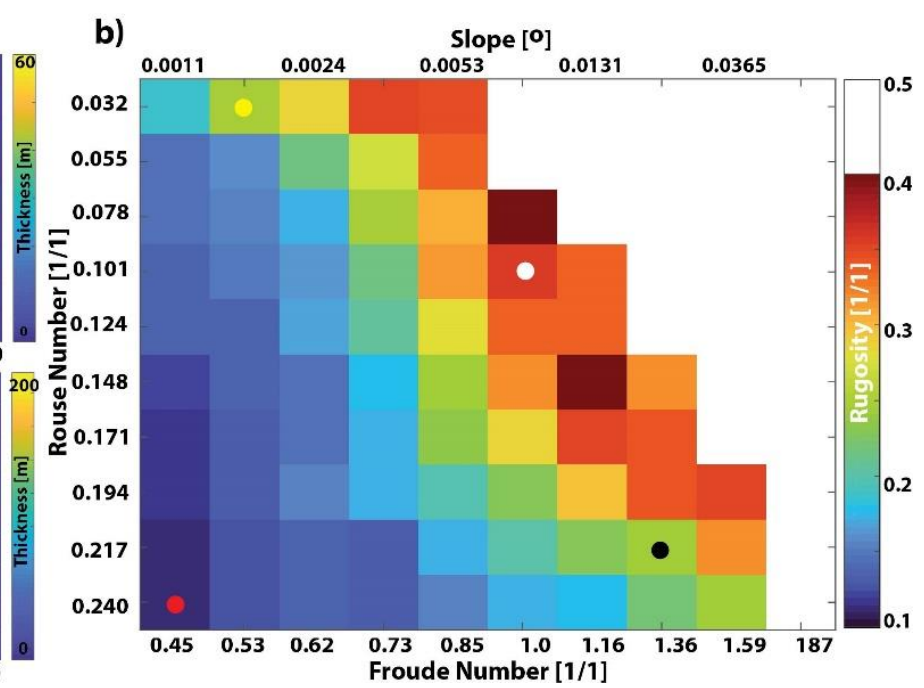

403

Fig.4 | Planform morphometry in simulated fans. a, Deposit thickness maps show contour used 404 to measure rugosity. The black semicircle defines a distance from the inlet at which half of the 405 sediment is stored in the model domain. The red contour is computed for a mean elevation along 406 the black semicircle. b, Matrix shows computed rugosity for all models. White area represents models in which input sediment largely bypassed model domains. Colored dots correspond to 408 rugosity measurements for fans displayed in Fig. 4a.

409 

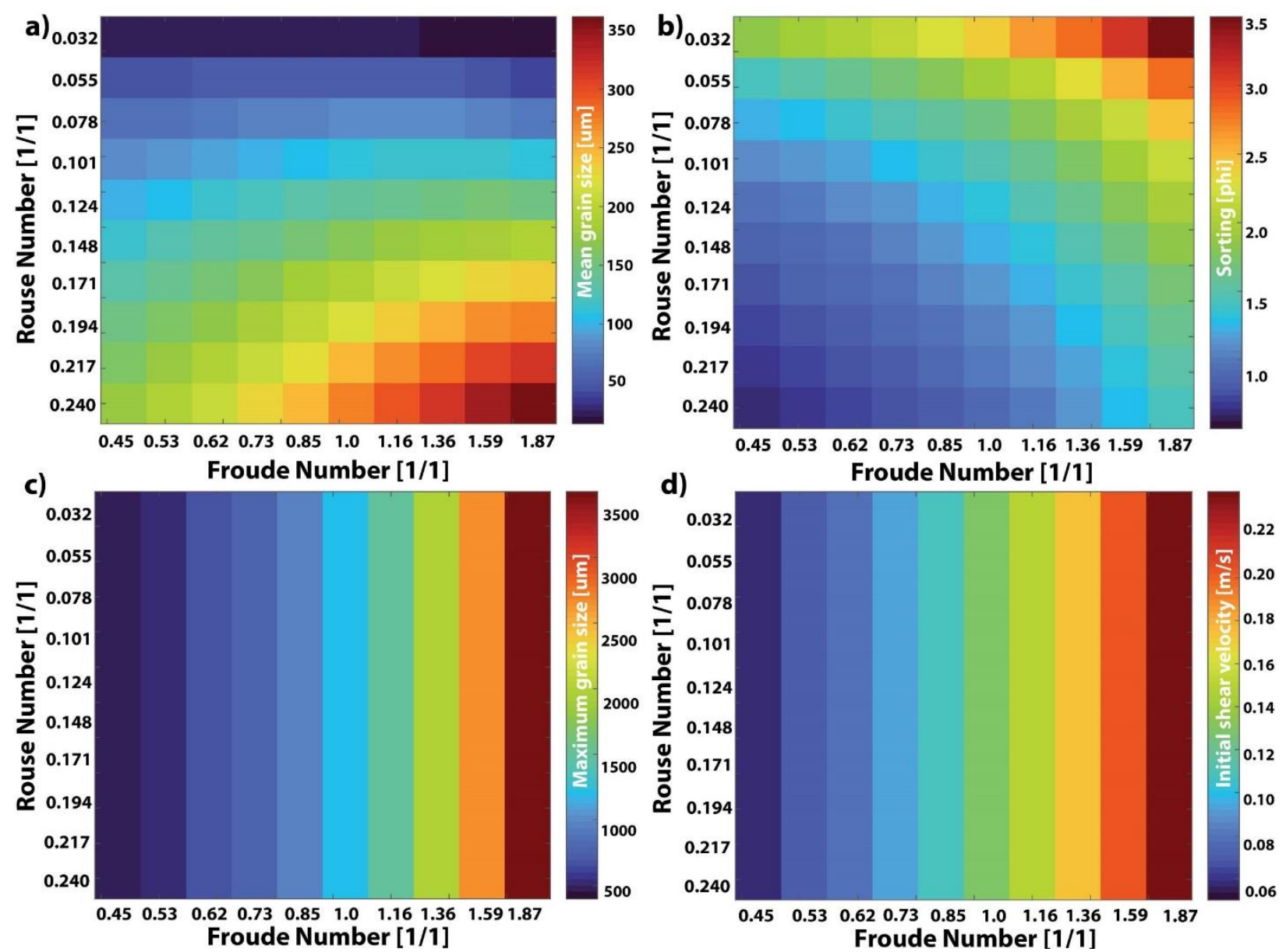

419 Fig.5 | Parameter design for the proposed dimensionless regime. a, Mean grain sizes, b. Sorting,

420 c. Maximum grain size, $d$. Inlet shear velocity. 
a) b)
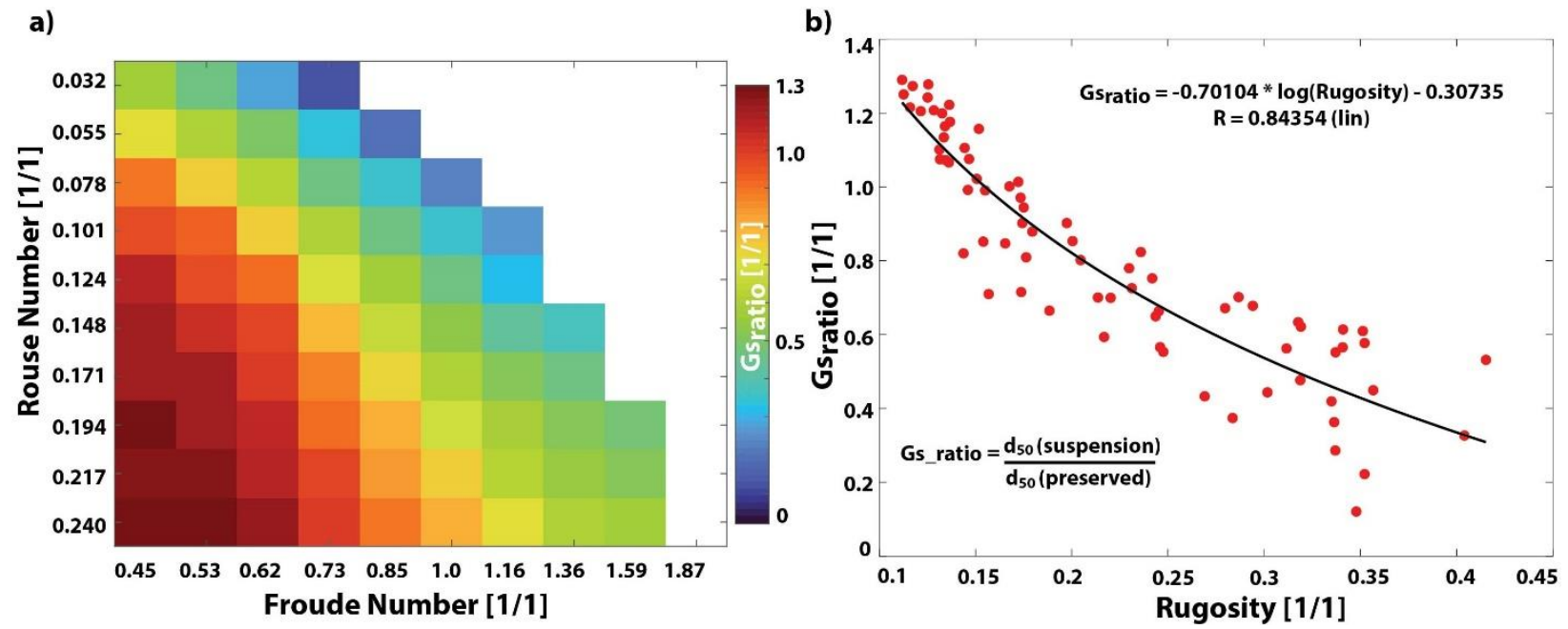

423 Fig.6 | Empirical relationship between grain size ratio and fan rugosity. a, Matrix shows grain 424 size ratio $\left(\mathrm{Gs}_{\text {ratio }}\right.$ ) computed for all models with significant deposit. This ratio is defined by median 425 grain sizes in suspension at the inlet to the median grain sizes preserved in model domains. $\mathbf{b}, \mathrm{A}$ 426 logarithmic trend is fit to the scatter plot of $\mathrm{Gs}_{\text {ratio }}$ and fan rugosity. This trend line allows for 427 estimation of mean grain sizes in suspension for a given $\mathrm{Fr}_{\mathrm{D}}$ and Ro value. 


\section{Supplementary Files}

This is a list of supplementary files associated with this preprint. Click to download.

- Subcritical.avi 